is possible for further substances to be included in the Convention whenever need arises. In the procedure to be used for this purpose, the precautionary principle is to be taken into account as appropriate. The criteria for the inclusion of further substances leave sufficient discretionary powers for scientifically-based decisions to be taken from case to case.

Over and above this, one must accept that the Convention contains further important measures such as those to reduce the release of POPs from stocks and from waste. It even goes as far as the obligation to make efforts to trace POP-containing products that are still in use, and contaminated bottles, and to dispose of them in an way that is environmentally compatible, or to decontaminate them. In this way, the instruments for the successful, precautionary protection of man and the environment from POPs have been created. How useful the measures agreed upon will be, will depend on how well the text of the Convention is implemented, developed and enforced.

\subsection{Secretariat}

As for the management of all other Conventions, the question of establishing a permanent POP secretariat, and where, will have to be decided sooner or later.

Since the beginning, the POP temporary secretariat is performed by a small number of specialists attached to UNEPChemicals in Geneva. This has proven to be very efficient and financially sound, both for the organization and for the State parties. Indeed,

- environmental affairs within the United Nations system are to a large extent assembled in Geneva - apart from the headquarters of UNEP in Nairobi - in the International Environment House and its Geneva Environment Network,

- practically all countries are represented in Geneva by a Permanent Mission to the UN and other organizations there are 149 of them;
- some $170 \mathrm{NGOs,} \mathrm{hundreds} \mathrm{of} \mathrm{journalists} \mathrm{of} \mathrm{the} \mathrm{interna-}$ tional press, the headquarters of many multinational companies are settled in Geneva, insuring the best possible impact and synergies for the work of any international organisations present in this cosmopolitan, multicultural and open city;

- today Geneva is one of the most sought after centres for conferences, international organizations and diplomatic activities, insuring the presence of the best infrastructure, interpreters and surrounding for the delegates, staff and their families.

The decision about the definitive location of the POP Secretariat will be taken - as usual - at the first Conference of Parties (COP-1). Switzerland has, since the beginning, been a solid supporter of the POP process and has consistently poured voluntary contributions in its budget. It will also finance the COP-1. Any country theoretically can apply for the transfer of the secretariat to one of its cities. Until now, only Bonn (Germany) has done so. This city hosts the UN secretariats for Climate Change and on Desertification.

\section{Outlook}

The success of the POPs Stockholm Convention created a considerable momentum worldwide for the protection of the environment from dangerous chemicals. This momentum also has to be used during the interim period. During this interim period, a conference of the INC will take place every year, the next in the year 2002. A lot of work has to start in order to implement the convention, especially in developing countries (PCB waste, obsolete pesticide stocks, dioxin emission reduction, and so on). We do not need to wait with the implementation until the Stockholm convention gets into force after 50 ratifications. Lets start now.

Received: June 25th, 2001

Accepted: June 27th, 2001

Online-First: June 29th, 2001

\title{
Second Announcement and Call for Papers
}

\section{First Baltic Symposium on Environmental Chemistry}

Tartu, Estonia, 26 - 29 September 2001

Under the auspices of: The Federation of European Chemical Societies, Division of Chemistry and the Environment Estonian Chemical Society • University of Tartu

The symposium topics include:

Sustainable Chemistry $\bullet$ Green Chemistry $\downarrow$ Anthropogenic Chemicals in the Environment $\downarrow$ Soil Analysis, Quality and Remediation - Water and Sediment Analysis, Quality and Treatment • Education in Environmental Chemistry

\section{Symposium secretariat}

Kaja Orupõld

University of Tartu, Jakobi 2, 51014 Tartu, Estonia

e-mail: baltenvir@ chem.ut.ee; fax: +3727375181 ; phone: +372 7375173

http://mega.chem.ut.ee/ baltenvir/symp.html 